\title{
REFLECTIONS ON THE NEGATION OF BLACKNESS//AFFIRMATIONS OF OUR CLAIRVOYANCE THROUGH CREATIVE HEALING PRAXES
}

\section{P. IFE WILLIAMS}

University of Wisconsin-Madison, BYP100

\section{ABSTRACT}

The negation of Black people is pervasive in the historical genealogy of white supremacy. Black society, and Blackness, as defined and fabricated by Western thought and action, exists in "outer-space" (Sexton, 2011). However, white constructs of Blackness are merely that-constructs. This piece acts in three parts: 1) an intellectual conversation with scholarly thought holders, 2) a space of personal reflection and interpersonal dialogue, and 3) pieces of prose and imagery that embody various forms of Blackness. This piece explores Black clairvoyance through examples of Black youth identities, social movement politics and practices, and affirmations of our creations, sacred spaces, and rituals. Our praxes are visible in our daily gestures even as we hold trauma-sometimes informal or episodic-but always seeped in love, creativity, ancestry, and spirituality, existing as moments of movement and healing resistance.
KEYWORDS

Blackness, anti-blackness, white supremacy, clairvoyance, creativity, Afrofuturism

\section{A GENEALOGY OF CLAIRVOYANCE} I was reminded of how estranged we, as people of colour and Black people in particular, are from the English language when my son echoed his first nonsensical conversational babbling. I was sure at that moment that not only was his spirited dialogue one of clairvoyance, but that he also embodied the presence of past lives and future ancestry. This spiritual connection is one we all possess; however, most often, we dispossess it as we progress into adulthood. As Black people, we forget (or pretend not to remember) because we are cornered by beliefs that tell us we do not belong, we are not worthy, we are better left for dead. The literal and figurative deaths of our people will easily have us believe this is true. It is a lie; we are divine.

This piece is crafted intentionally in a non-linear and multisensory format - weaving together reflexive prose, conceptual thought, and visual imagery. I have structured it this way because these are the ways I, and many other clairvoyant movement shakers, culture shifters, and space creators, experience and understand the world. Clairvoyance: derived from French clair meaning "clear" and voyance meaning "vision." This translates for youth in the twenty-first century social 
movement to a commitment to always remember that we are nothing less than brilliant and that we must activate clear steps to transform and expand our visions. In many ways, this piece in itself is also a project of resistance against the transactional nature of the English language that attempts to tell us how to exchange thoughts, write, or speak. By presenting knowledge through a creative, non-traditional, scholarly un-structure, I hope to disrupt any constrictions that suppress spirited forms of expression.

I invite you to spend time with me as I reflect on some of the ways that white supremacy attempts to negate Black people and Blackness. Struggle with me as I discuss anti-blackness and Afro-pessimism that situate Black people as non-human. Join me as I illuminate Afro-futurism as a way to ground ourselves in truth, but not limit our manifestation of futuristic visions and practices. Finally, inspired by my comrades in the Black Youth Project 100 (BYP100), a member-based activist organization dedicated to Black liberation through a Black Queer Feminist lens, and my work as one of the founders of BYP100's Healing \& Safety Council, join me in seeing and remembering all of the ways we affirm each other, our creations, our spiritual clairvoyance, and ourselves. This piece rests with these themes, front porch stooped on a warm spring evening, through scholarly debate, conversations with my child, and personal prose and reflections. Sit down, lean into, stay a long while, as we, Black people, affirm our creative healing praxes-remedies we have already cocreated and recipes we have yet to envision.

Why, some may ask, indulge in the invitation to (re) ignite our clairvoyance? Because our lives and our liberation depend on it. Because radically caring for ourselves, then each other, rigorously committing to principled struggle and nonpunitive forms of accountability - and doing so imaginatively and creatively-will see us liberated and unbroken. The patchworked quilts of our historical memory tell us so.

Because radically caring for ourselves, then each other, rigorously committing to principled struggle and non-punitive forms of accountability-and doing so imaginatively and creatively-will see us liberated and unbroken.

\section{VISION-THE LANGUAGE OF} BLACKNES S

Black people face profuse constrictions and suppositions, yet we survive. Toni Cade Bambara reminds us that English is not our native language; we are limited by its inadequacy to express our essence. Similarly, white constructs of life and being do not belong to us, nor do they hold us. In Conversations with Toni 
Cade Bambara (2012), she says:

The unwillingness of the cultural brokers and powerbrokers of this society to acknowledge smoke signals, the drums, or the existence of intelligence channels other than their rationality and the logic result in a language, namely English, that does not accommodate discussion of those phenomena outside of the Western Logic. [...] You can get a lot of trade done with English. But you would find it very difficult to validate the psychic and spiritual existence of your life. Consequently, we pretend. We pretend that we're not clairvoyant, we buy glasses. (p. 91)

the language of clairvoyance is clear vision. why sometimes we pretend to forget; why we buy glasses -I do not know, perhaps

the white gaze of contempt (sometimes) causes distorted vision.

dare i say, i do not own glasses, for $i$ will not pretend to not know our clairvoyant worth. however, i have no other written tongue than English.

i am hydrated by creativity and draw from my palette of magic. i am grateful for the nourishment i receive from my ancestors' labour.

this is why and how i create sacred spaces, wonders of creative healing praxes.

i'm not a poet. but sometimes

images and visions come to me, first asking to be set out on altar as words then actions

always preferring to contain some sort of antithetical syntax.

\section{CONTENDING WITH THE GLASSES OF A N T I-BLACK N ES S}

have you ever seen something and felt it deep in your bones? have you ever remembered something and felt it deep in your heart? have you ever created something and felt it deep in your memory? i felt this as i drew the iconic etching of our people, enslaved, violated, inflicted by the construction of race turned anti-blackness. the reality of us stowed -6 feet by 1 foot 4 inches of space (or less)-on the British slave ship "Brookes", under regulated slave trade Act of 1788. an image used by abolitionists to depict some of the strongest illusions of Black inferiority. what 
an eerie feeling, "breathing a breath of ancestors life at every brush stroke" (Williams, 2017c).

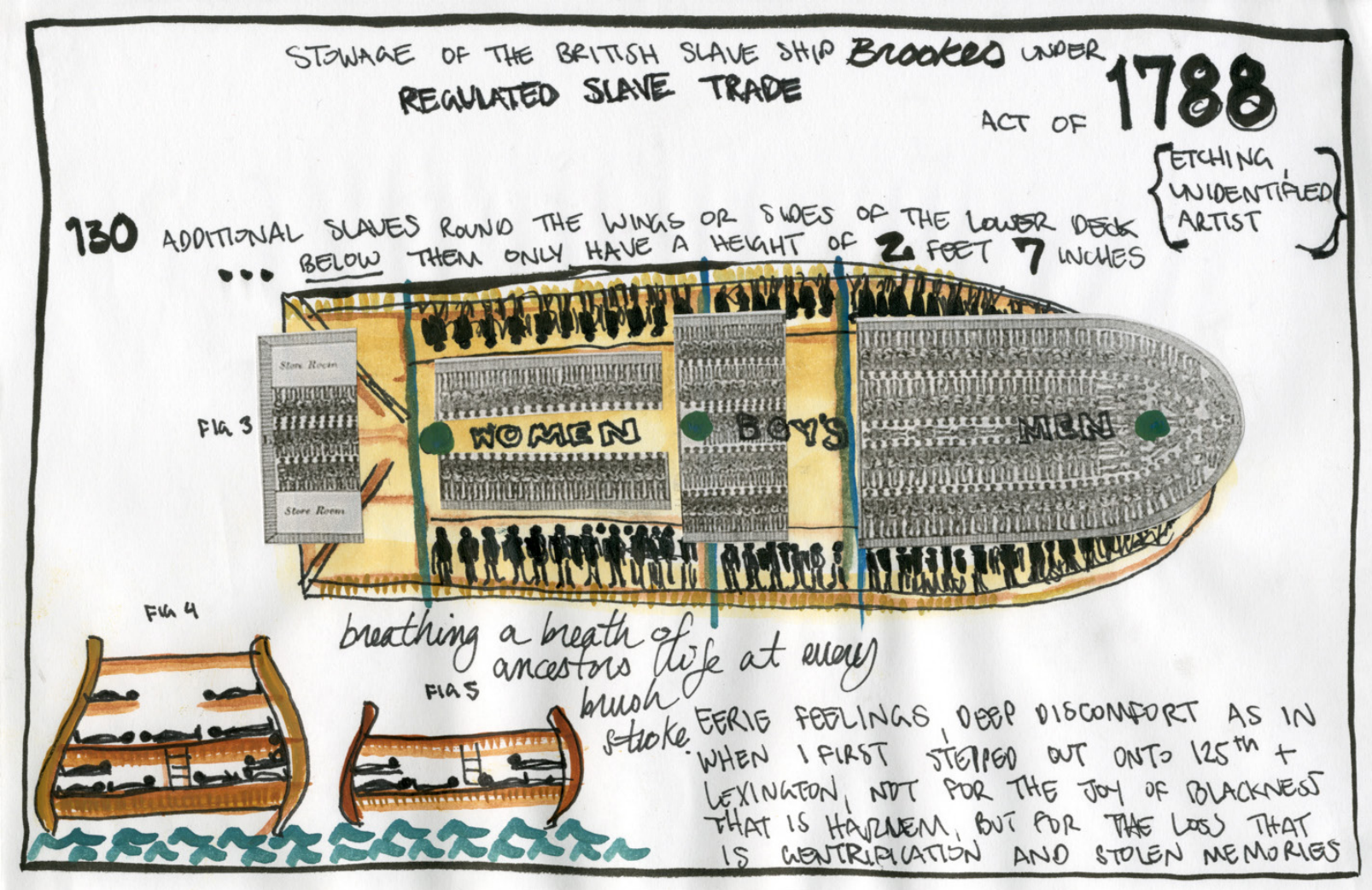

(breathing a breath of ancestors life at every brush stroke, P.I. Williams.)

"ANTI-BLACKNESS is GLOBAL" A statement i scrolled past one morning as $i$ half-heartedly browsed through internet memes, always vigilant that I may fall upon the most recent awful news. global anti-blackness, a simple, yet extremely heavy, statement. how is it that Blackness has become synonymous with tainted and cracked? as $i$ am composing this piece, $i$ also hold the stories and horrors of enslaved migrants in Libya being sold and auctioned. of what would have been Trayvon Martin's 23rd year of breath. of mothers locked in cages and babies being cared for by their (barely older) siblings.

Anti-blackness is a constant negation of Black life, Black people, Black being. Contending with the fact that we can no longer wear glasses as corrective lenses demands us to dismantle the narrative about Black people that equates Blackness to nothingness and/or always anything. My call is to disrupt the motionlessness of anything that claims to be constant-because we know nothing is unchanging; nothing is a/ways. Imagine I were to tell my six year old child, "You are always wrong, always messing up, always causing trouble, 
always trouble." Or for example, always contesting "Black rage," but ignoring the passion and love that, like tea, is steeped as rage's kin.. And yet, the "always" of white supremacy must be seen, it is "built on the extermination of Indigenous peoples and the expropriation of their Lands, the enslavement, oppression and exploitation of Blacks, and the subordination and exclusion of brown-skinned peoples as citizens, all in an effort to create a white state" (Dei, 2017, p. 47). We must struggle with the deathliness of the political State, which currently is always antiblackness:

"our images.

always half.

always burning.

always welt.

always bent.

always garish.

always crawling.

always high.

always drunk.

always severed.

always flayed.

always vomiting.

always laughter laced with choking.

always chained.

$\ldots$

--emotional porn (the black image industry)"

nayyirah waheed | from 'nejma' 1

pause. and Breathe, deeply.

---reconnect with the timelessness of this moment. remember, we are clairvoyant.

\section{AFRO-P ES S I M I S M : R EF LECTION S ON THE NEGATION OF \\ B L A C R N ES S}

Arguably, the conditions that encompass the relationship between white constructs of society and Blackness are complex. Antiblackness (tries to) contain Black being, while Afro-pessimism seeks to explain that containment. Afro-pessimism is a series of interwoven positions on anti-blackness and its effects on Black people. Afro-pessimists Frank Wilderson and Jared Sexton suggest Black people are in a constant antagonistic relationship with humanity. Sexton (2011) states:

1. For the complete poem, see Nejma by Nayyirah Waheed (2014). 
Black life is not social life in the universe formed by the codes of state and civil society, of citizen and subject, of nation and culture, of people and place, of history and heritage, of all things that colonial society has in common with the colonized, of all the capital has in common with labor-the modern world system. Black life is not lived in the world that the world lives in, but it is lived underground, in outer-space. (p. 28)

In other words, Afro-pessimists state Black people are socially dead. Meaning, Black bodies do not have the same rights and protections as other people. Black people are not privy to the same access to resources or the same intention of safety as other non-Black humans. Black people are disproportionately finding themselves expelled from schools, locked up in cages, at the barrel of a police gun, not knowing if this moment holds a last breath. pause, and Breathe, deeply.

Ample public discourse and policy support the conceptual claim put forth by scholars such as Moten (2013), Hartman (1997), Sexton (2011), and Wilderson (2010) that Black people are not seen as human. Recall the three-fifths compromise as an example of "not human." This clause, instituted into the United States Constitution in 1787, was an agreement to "count three-fifths of a state's slaves in apportioning Representatives, Presidential electors, and direct taxes" (Digital History, 2016). During interim periods, this strongly positioned the southern states for political power and control, which supported the continuation of slavery. Black subjugation has been and continues to be justified because we are not human and yet often seen as "super human-like."

Another example welded into the United States' political typography of Black-bodies-existing-in-a-space-of-non-human yet super human-like is the "super-predator" narrative. In an article written by criminologist and Princeton political science professor John Dilulio, Moral Poverty (1995), Dilulio states:

While the trouble will be greatest in black inner-city neighborhoods, other places are also certain to have burgeoning youth-crime problems. [...] Moral poverty begets juvenile superpredators whose behavior is driven by two profound developmental defects. First, they are radically present-oriented. [...] Second, the superpredators are radically self-regarding. [...]They are perfectly capable of committing the most heinous acts of physical violence for the most trivial reasons (for example, a perception of slight disrespect or the accident of being in their path). They fear neither the stigma of arrest nor the pain of imprisonment. (pp. 1, 3-4) 
blatantly deny/pretend to forget the impact of slavery, the dehumanization of Black people at the hands of anti-blackness. sometimes, $i$ wonder if those who are complacent to white supremacy live in the same world that $i$ live in?

this emptiness in false narratives driven by fear and control reminds me of the white gaze.

moves me to call upon all the visions we hold for our young people and ourselves.

the visions that have birthed the reasons why we are still living.

Dilulio continued to develop the super-predator construct in the book Body Count (1996). Hillary Clinton then popularized the term, quickly followed by campaigns, strategies, and policies from former President Bill Clinton's administration that activated this rhetoric (Bernstein, 2014). The rhetoric of Black criminality is also perpetuated through the media and other distorted white narratives. This story of super-predators has continued to plague Black people.

These are two examples of many that support the white supremacist belief of Black partial citizenship-where we are never fully human, yet also super human-like. Super humanlike has meant medical tests and experiments that suggest we feel no pain. The super human-like narrative positions Black women as unwaveringly strong, always able to handle the worst circumstances and still always survive, or die. These myths sit like a relapse in white memory that fails to acknowledge-even though we are divine-that we are still human. Remember, nothing can always be working; always be standing, always be building. Rest. Reconnect with the timelessness of this moment. What does it mean for Black people to live in a world of antiblackness? It means we must create rooms, not borders. It demands that we not limit the pleasures of life to moments of healing from scarcity and tyranny, but as spaces we award ourselves often.

\section{AFRO-F U T UR I S M: CLEAR ING OUR SIGHT FOR (NON-BINARY) I M A G I N A T ION}

Awarding ourselves pleasures and the full recognition of Black being, in our living, breathing bodies, requires a complete shift in how Blackness is understood. Afro-futurism provides a framework to reimagine Blackness: it rests on intersecting notions of "imagination, technology, the future, and liberation" (Womack, 2013, p. 9). Afro-futurism asks us to create heaven(s) on earth. It is a way of imagining possible futures through a Black cultural lens that does not limit future life to worlds created by whiteness. 
This is not easy or romantic work. Afro-futurism holds Afropessimism patiently, acknowledging the nearly insurmountable task of shifting the language of anti-blackness and white supremacy that sees Blackness as unworthy of humanity. Afrofuturism reminds us that if our ancestors had accepted that our social death is permanent, we would not be alive today to affirm that we are very much living.

Tryon Woods (2007) argues that to produce "A world of mutual human recognition requires adjusting the society's epistemological and ontological foundations" (p. 327). I understand epistemology to mean how we come to know, the methods and values that lead us, and ontology to mean the essence of how we come to be. For example, an epistemological recognition of the expansion of what it means to be Black and queer includes GENDER LIBERATED BATHROOMS, ${ }^{2}$ not only as a sign that symbolizes a recognition of the gender continuum (our values), but also a method that informs "how we come to know." The reliance on a gender binary that still largely exists in dominant society and exists as a formulation associated with a colonizer approach ${ }^{3}$ is one of the ways that white society has pushed us into un(knowing). We must reorient ourselves to different perspectives. The gender binary is one example of

The reliance on a gender binary that still largely exists in dominant society and exists as a formulation associated with a colonizer approach is one of the ways that white society has pushed us into un(knowing).

many that perpetuate false dichotomies, including good/evil, civil/uncivil, always/never.

Since I am expressing a clear criticism of the tendency to explore concepts through binaries, why am I discussing the construction of society and Black being in white and Black? Call it hypocrisy, lack of consistency. My reasons are simple. That is to say, it is not necessarily a colour or race thing, it is an experience-of-life-due-to-the-construction-of-race-by-whitepeople thing. When I talk about the white negation of Blackness,

2. Gender Liberated spaces are a standard practice within BYP100.

3. During the early stages of my writing, I included the language of "decolonization" as a frame to understand "moving away from whiteness/ reclaiming Blackness" including how we shape our worldviews and practices. Tuck and Yang (2012) have complicated this framing for me. While the argument of decolonizing still resonates, I understand it is complex. The authors state, "When we write about decolonization, we are not offering it as a metaphor; it is not an approximation of other experiences of oppression. Decolonization is not a swappable term for other things we want to do to improve our societies and schools. Decolonization doesn't have a synonym" (p. 3). I intend to further explore if and how decolonization as a praxis folds into the Black liberation movement. 
I am not talking about all white people. I am talking about the white supremacist ideologies and practices crafted and maintained by (most) white people as well as (some) non-Black people of colour. When I talk about Black and white, I also recognize that (half) my (French) ancestry holds a distinct connection to the oppressive constructs that I am calling into accountability. However, as a Black mixed-race queer woman, my disruption to the concepts of white cis-heteronormativity ${ }^{4}$ gather on my experiences of antiblackness.

These non-binary, non-heteronormative genealogies exist outside of the spaces dominant society has cornered us into, outside of the ways it has instructed or coerced us to believe, to be, and to hold each other and ourselves. These spaces are enamored by the white gaze, yet often misunderstood and almost always appropriated. These spaces have non-Black people asking questions (in their heads or as inquiries to their one "I-have-a-Black-friend") to which I will provide some of many possible answers:

"Why are Black people so (characteristically) Black?" Characteristically Black... as in? Westside brilliant. Intellectually ratchet ${ }^{5}$. Afropunk. Set It Off. Do the Right Thing. Boyz in the Hood. Black as in... characteristically how, who, what and where.

"Why can't 'they' get (it) together; create sustainable associations, thriving neighborhoods, 'civil' societies?"

I shake up some hands on the right block. Block club president, night watch. ${ }^{6}$

Black clubs, community watch, corner store cyphers, front porch stooping. Always police surveillance, always community watchin'.

"When will they let go of the slavery thing?"

Never. Unless, maybe, the acknowledgement and action towards true abolition unfolds. But really, never. It is stitched in our historical memory.

4. Someone who is "cis-gender" identifies with the sex and gender assigned at birth. For example, a cis-male is assigned male at birth and identifies as male in adulthood. Heteronormativity is a worldview that promotes behaviors associated with heterosexuality, such as viewing behaviors and sexuality between opposite sexes as normal or preferable.

5. I was first introduced to the term "intellectually ratchet" through a collective in Madison, WI, of the same name: see https://www.instagram. com/intlctlratchet/.

6. Chance the Rapper on "LSD" (Jamila Woods ft. Chance the Rapper, 2017). 
A side note on slavery and abolition: Tuck and Yang (2012) write: "Enslavement is a twofold procedure: removal from land and the creation of property (land and bodies). Thus, abolition is likewise twofold, requiring the repatriation of land and the abolition of property (land and bodies). Abolition means self-possession but not object-possession, repatriation but not reparation" (p. 30).

sometimes i question/critique myself for talking about Black so much, talking through and to white so much; about the ways white tries to other Black. i question if it's healthy or safe for my child to know about the woes of Black and white, the successes of Black, most often, only through the assimilation as "white", or the triumphs of Black defined through white terms of success. the complexity of Black, that has been simplified to Black versus white. $i$ wonder if all my energetic resources and labour could best be spirited if $i$ built my own world (a collective world). i ask myself, what are my blinders? in what ways am i naive to the layered experiences of Black people that limits my understanding of our potential to be unbroken?

I wonder how my ancestors found answers.

A little over a year ago, a few months before my maman passed, she had a session with a friend of mine, a healer, Reiki practitioner, ancestral conduit, and mother, among many other things. One of the messages that my mom received during that session was:

"we are proud of you" - from your ancestors.

it's strange and wonderful how the Universe works. shortly after my maman's transition in February 2017, i asked her permission to lift the words passed down from her ancestors that were written in the pages of her journal, place an offering in the form of an altar, display some of her most cherished moments. i refer to those words regularly to help hold me in this work. $i$ know it is a message that my ancestors call over me.

Indeed, it is this connection to our ancestors and our commitment to the flowering breath of future generations that holds us to the rituals of clairvoyance. why you ask about the absence of Black (civil) society, stupefies me. perhaps you have forgotten we "do not wear glasses" and, in fact, these spaces you call lacking, are ones of underground worlds, of outer-space, of visionary spirituals, of healing resistance. indeed, it is this connection to 
our ancestors and our commitment to the flowering breath of future generations that holds us to the rituals of clairvoyance

kinda like the story that we are our "ancestors' wildest dreams"'.

\section{ACTIVATING OUR VISIONS THROUGH CREATIVE HEALING \\ PR A X ES}

the image "[a] creative healing praxis//[an] ecology of Black trauma" (Williams, 2017a) is a visual representation of (some) of the rituals we as Black people hold in our possession and a conceptual framework of the traumas we hold in our hearts and our bodies. this work is a labour of scholarly-activism, experimentation and deep love-it is very much connected to the work $i$ have been doing since 2015 through the Healing \& Safety Council (HSC) with my BYP100 squad, a member-based activist organization dedicated to Black liberation through a Black Queer Feminist lens. i do not profess "ownership" of the work, but do extend gratitude to the terms that i conceived: [a] creative healing praxis//[an] ecology of Black trauma. these are rituals rooted in our Black radical traditions. i am simply remembering. and calling in a resurgence of all of the ways in which we can manifest our legacy and stimulate our clairvoyance.

creative is our commitment to visioning and activating Afrofuturistic liberation.

healing is our commitment to being unbroken.

praxis is our commitment to a constant, cyclical practice of rigorous reflection and action.

our creative healing praxes are labours of political warfare, compassionate care, and radical love.

our creative healing praxes deeply remember our history and revere our.

our creative healing praxes conjure our spirituals: the elements of earth, air, water, and fire, and honour our non-human relatives. our creative healing praxes use creativity to imagine an abundance of recipes and remedies to the conflicts we face.

our creative healing praxes do all this and more through:

holistic energy,

generative culture,

7. The phrase "I am my ancestors' wildest dreams" was first coined in New Orleans, LA and become popularized through New Orleans-based public artist Brandon Odum (n.d.). 
political art,

principled struggle,

enthusiastic consent,

rigorous accountability,

daring love,

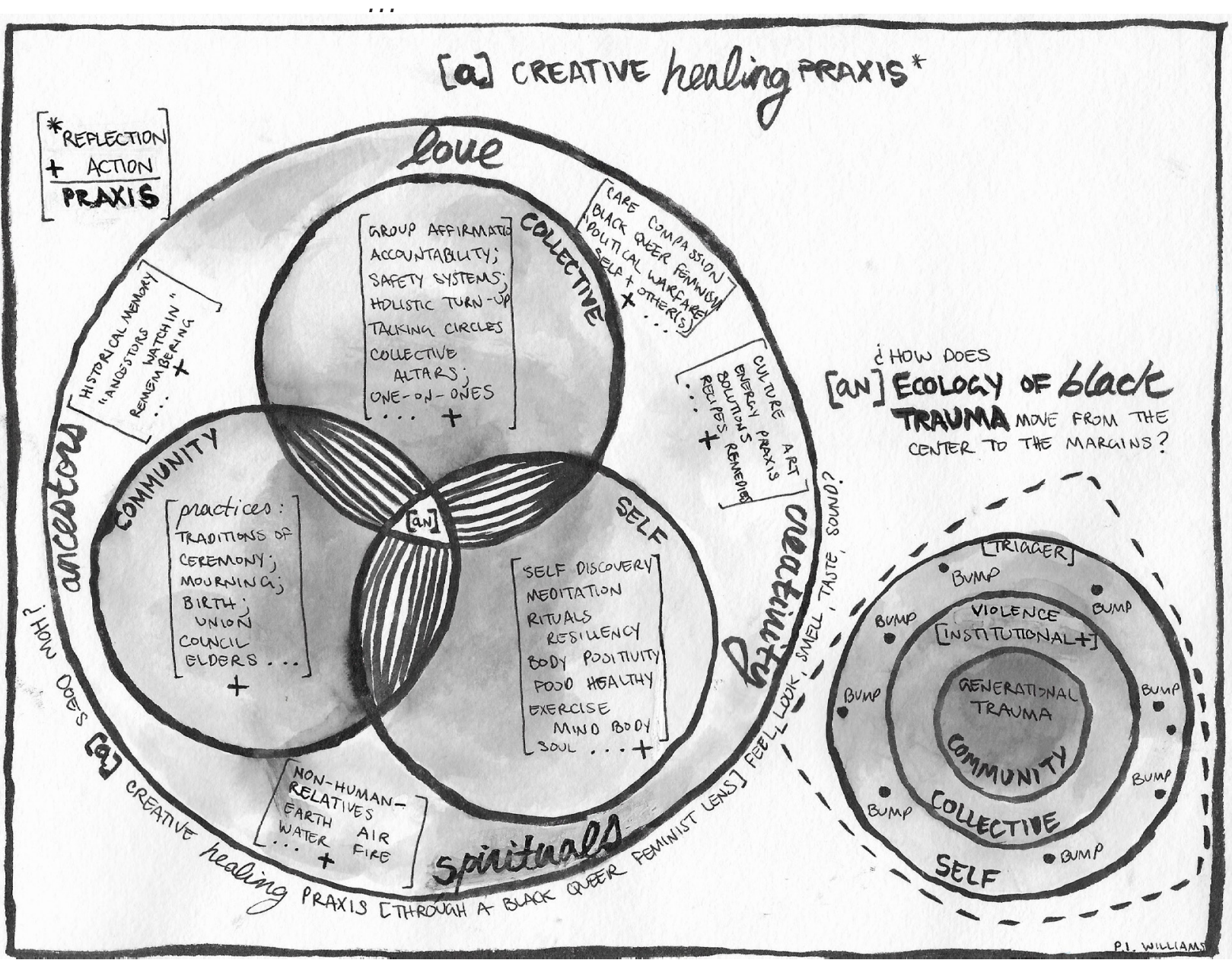

([a] creative healing praxis//[an] ecology of Black trauma, P.I. Williams, 2017a).

Paulo Freire (1970) defined praxis (praxis is the singular of praxes) as "reflection and action directed at the structures to be transformed" (p. 126). Black creative healing and resistance in the twenty-first century includes reflection and action, and a Black Queer Feminist ${ }^{8}$ praxis as theorizing and application that is cyclical, non-binary, and interdependent. We envision these rituals collectively through moments of constant collaboration. The

8. A Black Queer Feminist lens allows us to see and understand that our identities make us vulnerable to multiple types of oppression. Therefore, liberation for all Black people can only be realized by lifting up the voices and experiences of historically silenced and vulnerable groups within Black communities. Specifically, queer, trans ${ }^{\star}$, femme, poor, disabled and undocumented bodies (Green, Taylor, Williams, \& Roberts, in press). 
image "[a] creative healing praxis//[an] ecology of Black trauma" (Williams, 2017a) provides a visual depiction of the possibilities of creative healing praxes as well as the acknowledgement of Black trauma. I have begun to develop these frameworks through both my community practice and research; it is a framework of praxis, intended to inform action after thought, thought after action.

The work of creative healing praxes includes imagining and actualizing systems of safety and support for Black people that have all of our best interests in mind. Moving into creative healing praxes includes the values of love as praxis, creativity as praxis, ancestors as praxis, spirituals as praxis. The individual, collective, and community are equally central to this ecology because affirming visionary and creative spaces does not happen in a silo, it happens in a sphere. Clairvoyance-clear vision-is our path to creative healing praxes.

In BYP100, the Healing and Safety Council (HSC) is a body of members dedicated to cultivating and supporting self-determined forms of healing, harm reduction, and cultural production. HSC exercises the tenets of the healing justice framework (Page, 2007) to activate creative healing praxes that focus on prevention, intervention, and transformation. This looks like the creation and provision of an ongoing base of care modules, community based accountability to mediate harm including interpersonal conflict, and transformative rituals through culture creation and visioning. At the individual level, HSC invites our members to commit fully to the life-long process of healing. These recipes include, for example, engaging in self-discovery, meditation, exercise, healthy eating, daily care rituals, and affirmations to self. At the collective level, we invite our members to participant in building collective altars, engage in exercises of group affirmation, participate in talking circles, and experience Black joy by cultivating spaces for holistic turnup. We engage in holistic turn-up by activating and transforming energy. BYP100 refers to this as holistic energy, "the process of providing an interdisciplinary approach to artistic articulation, erotic truth, music, and anti-oppression work" (BYP100, 2017, p. ii). Our care modules include safety systems such as the Safety Plan, which asks members to outline how best to support them during moments of unrest. We have developed curriculum around enthusiastic consent to help reduce the potential for nonconsensual sexual experiences and/or other non-sexual bodily violations. We are creating curriculum to discuss the roles of masculine of center members and to mitigate the behaviors and actions that rest on tenets of patriarchy and violence towards women, queer, trans ${ }^{\star}$, and gender non-conforming people. We are creating vessels to discuss principled struggle, community accountability, colourism and other important praxes and modes of healing resistance. Additionally, we lean into community level 
practices that include Black traditions of ceremony, mourning, birth, council, and other rituals. Our journey has been a joyful experiment-generative, challenging, yet visionary. The anthology of these praxes can transform the ways in which Black people experience each other and ourselves.

\section{ACRNOWLEDGING AN ECOLOGY OF BLACR HOLDIN'}

Not wearing glasses means we must acknowledge and hold our traumas. Remembering the impacts that violence and white supremacy have had on Black people, we understand that trauma is not inseparable from creative healing praxes. The oppressive ideologies and policies that we have endured inform [an] ecology of Black trauma interwoven and embedded experiences of how and why we experience violence and harm. Asking ourselves how an ecology of Black trauma moves from the center of our experiences to the margins is the visionary work of seeing Black people as more than the violence we have endured at the hands of white supremacy.

ecology is our interconnectedness - our being - at the individual, collective, community and universal levels.

Black is everything beautiful, immortal, and abundant.

trauma is recognition of being broken and constricted.

Seeing Blackness unbroken is the work of unraveling the threads of hundreds of years of psychological, emotional, physical, and spiritual violence so that brokenness does not dictate how we move forward.

Seeing Blackness unbroken is the work of unraveling the threads of hundreds of years of psychological, emotional, physical, and spiritual violence so that brokenness does not dictate how we move forward. It is the work of multiple lifetimes. Of our ancestors and future ancestors. It is about the ways we commit to honour ourselves and hold each other. How do we acknowledge the trauma and harm we have experienced without allowing it to dictate our visions? Carrying trauma and holding healing shows up differently for individual people and is particular to the historical memory of a community. One thing is certain, Black people be holdin':

We be-holdin' space. We be-holdin' meetings. We be-holdin' circles. We be-holdin' processes. We be-holdin' mediations. We be-holdin' trainings. We be-holdin' workshops. We beholdin' names. We be-holdin' naming. We be-holdin' time. We be-holdin' pain. We be-holdin' disappointment. We 
be-holdin' failure. We be-holdin' trauma. (Green, Taylor, Williams, Roberts, in press)

All of these compounded insults to our bodies, minds, and spirits accumulate to inform an ecology of Black trauma.

As depicted in the inner most embedded circle of [a] creative healing praxis//[an] ecology of Black trauma (Williams, 2017a) possibly closest to our hearts, yet furthest from our daily experiences or immediate memories, is the historical trauma Black people all hold. The forced movement of Blacks in the African diaspora, in the United States context in particular, is a history seeped, soaked, and stained in anti-black ideology and policy. Slavery is a historical memory that all Black people share. It is the experience of breathing a breath of ancestors' life at every brush stroke). At the collective level, we hold a relationship to trauma and institutional violence that varies based on more visceral and tangible daily experiences. For example, Black queer members of BYP100 are subject to forms of violence particular to activists in the twenty-first century, such as living in the wake of an administration led by $45^{9}$ and organizing under the guise of the FBl's Black Identity Extremist list.

Additionally, raw exposure to violence through various modalities exacerbates these experiences of trauma, be it through the visual barrage of police shootings and death in mainstream news, hateful rhetoric on social media platforms, or violence in the immediacy of one's own neighbourhood or home. Our experiences of individual trauma such as "loss, interpersonal violence, food and home insecurity" (BYP100, 2017, p.1) informs a relationship to trauma that exists at the skin level: that which we likely feel most strongly on a daily basis. Indeed, individual trauma can sometimes trigger us by causing us to relive an experience of harm that feels almost insurmountable. However, harm and violence do not have to become traumatic. A BUMP (Taylor, personal communication, 2017) ${ }^{10}$ is a discomfort that we acknowledge and sit with in the moment, and eventually are able to move beyond. Gently listening to and responding to the needs of our bodies and minds in the moment can help move us from experiencing all violence as traumatic, all trauma as triggering. Experiencing breath can move us to feel a small BUMP rather than an insurmountable pain. Breath brings us closer to being unbroken.

what does it mean to be unbroken and find belonging in a country where my ancestors have experienced so much holdin'?

9. Donald Trump 10. I first heard the term BUMP from Je Nae Taylor, who shared she had received the council from a friend. 
where being unbroken and finding belonging

rolls most easily off my tongue in non-English.

twists through my creative fingers,

dreams into my orgasms,

floats in the language of my whispers.

dances in and through my creativity.

what does it mean to belong in a country where my ancestors have never belonged?

it means waking up every day and finding belonging in the small gestures.

One day I asked my (then) five-year-old child, "What makes you feel like you belong?"

The response I received was:

"Huh?"

I laughed. . . . Then I asked:

"What makes you feel welcome, or that you are safe and comfortable?"

"Mama, why do you always ask me these kinds of questions? Sometimes it makes my brain think too much about Trump and other things that make me scared."

We discussed this for a moment, and I promised to ask (fewer) of these types of questions, saying, "I ask because I love your answers. They make me smile and think."

To which the response was:

"I belong, I belong where I live."

\section{AN INVITATION TO (RE)VISION} B L A C K N ES S

Black spirituality and creation serve as conduits for visions. Our spiritual ontology, how we come to be, has never been broken. This is apparent in the "realization that the spirit and spirit ontologies cannot be and were never colonized" (Dei, 2017, p. 50). Our clairvoyance is protected. Black people decide how we make sense of the world and how we show up for one another. Coupled with traditional practices, our millennial forces (must) include both radical political strategy and intentional recipes for healing and safety as well as a deep commitment to community accountability. These are some of our contributions to liberation; pieces of the lineage that will contribute to our collective clairvoyance and will bring the next generation one-step closer 
to the freedom we, and our ancestors, have been imagining for centuries. I am humbled to participate in the visioning of a portion of this genealogy. Our political, spiritual, and healing resistance lives in the images we create of ourselves that love Blackness, in the quilts our grandparents hand stitched, the stories our nanas retold, the family portraits our altars hold.

You might ask, "how do we envision liberation when we've never known it?" to which I say, that is the work of Afro-futurism. Imagining ourselves outside of a history of trauma and untied to oppression; visions of worlds we create from this vantage point, this is healing resistance. This is our space(s) of spirituals and creative healing praxes.I strongly believe that is what carried us from the stowage in slave ships to now, still breathing. This commitment to an Afro-futuristic vantage is what moved and continues to move us into the planting of seeds, like my child, who will propel us into new cosmos. Robin D. G. Kelley (2002) suggests:

Progressive, social movements do not simply produce statistics and narratives of oppression; rather, the best ones do what great poetry always does: transport us to another place, compel us to relive horrors and more importantly, enable us to imagine a new society. (p. 9)

Afro-futurism is an invitation to creative healing praxes, to reimagine the limiting frameworks that have harmed us and/or do not serve us. These praxes are also projects of healing resistance that include affirming Blackness. Projects that continuously uphold and love all forms of Blackness and are still critically assertive about acknowledging the ways that women, trans*, queer, gender non-conforming, and disabled folks are most impacted by anti-blackness. These praxes are sacred spaces revolutionary collective parenting, altar work, family walks, deep breaths, multiple orgasms, Epsom salt baths. These praxes of healing resistance are Sankofa in practice-coming back to our roots to move forward. What is the intellectual language of our ancestors? How does our historical memory and wisdom inform our collective concepts and practices? How are we decentering whiteness and centering the traditional frameworks of our Black radical genealogy? "Radical simply means grasping things at the root" (Davis, 2006). Collective movement allows us to lean into our praxes through radically grounded visions. For many youth in the Movement for Black Lives (M4BL) ${ }^{11}$, this "coming back to" is remixed in "millennial" recipes of political practice and radical love, because our bodies, our creative healing praxis are always evolving.

Additional questions include: what recipes might we

11. M4BL is commonly referred to as the \#BlackLivesMatter Movement. 
come to embody if we were to imagine ourselves outside of a white supremacist society? What is Black "outer-space" (Sexton, 2011, p. 28) in inner-space? How does [a] creative healing praxis [through a Black Queer Feminist lens] feel, look, smell, taste, sound? ${ }^{12}$ How do we, how can we, more intentionally treat each other and affirm ourselves in this work? Ruminating on these and other questions can serve as one of our main conduits to clairvoyance. My commitment to exploring and visioning new forms of creative healing praxes is not to be mistaken as naiveté around the structural hurdles and violent systems that continue to restrict us. This work must sit alongside political organizing and other modes of systemic abolition, and healing justice, all existing as revolutionary comrades. Our transformation is not simply a question of personal will, it is a matter of collective thrust.

We must sit with this work. Head on. Hold it. Cry with it. Breathe. Remind ourselves that we are clairvoyant. And that to have clear vision we must

We must sit with this work. Head on. Hold it. Cry with it. Breathe. Remind ourselves that we are clairvoyant. show up for ourselves first, and then each other. Regularly, always, but not to exhaustion. A friendship love letter. An enthusiastically consented touch. We must also sit, gently, with our trauma and pain. Saidiya Hartman (1997) discusses her process of documenting "mundane" materials, saying, "I hope to illuminate the practice of everyday life -specifically, tactics of resistance, modes of self-fashioning, and figurations of freedom" (p. 11). It is this emphasis and commitment to the daily affirmations of Black "outer-space" in inner-space that I am conjuring.

our bodies.

always laughing.

always crying.

always holdin'.

always moving.

always waiting.

always running.

always dreaming.

always freedom.

always transform.

always growing.

always (loving) shade. (shade-o-meter/shade tree.)

always affirmations.

always turn-up.

always holistic energy.

12. This question is included in my original diagram [a] creative healing praxis//[an] ecology of Black Trauma (Williams, 2017). 
always dancing.

always singing.

always chanting.

always praying.

always collective.

always inside joke.

always apple juice.

always daydream.

always dream.

always innovating.

always culture.

always stooping.

always cyphering.

always corner stores, actually on the corner.

always small.

always biggie.

always fly hustling.

always hustle.

always swaggy.

always hooping.

always showing up.

always Chicago two steppin'.

always jumping.

always heavy breathing.

always breathe.

always pillow talk.

always whispers.

always shouting.

always rage.

always compassion.

always up.

always awake and always woke.

always Sankofa.

always remember.

always memories.

always stories.

always cooking.

always recipes.

always ingredients borrowed from auntie's house.

always remedies.

always stand up.

always sit down.

always remixing.

always hip hop.

always learning.

always curious.

always question.

always affirm. 
always babies.

always laughter sprinkled with happy tears and giggles.

always fam.

always ride or die.

always got your back.

always spirit kin.

always chosen family.

always kinship.

always spiritual.

always sacred space.

always \#SayHerName.

always circles.

always trauma.

always healing.

always healing.

always healing.

always clairvoyant.

always creating spirituals to bring ourselves back to self.

--affirmations (the Black Joy Experience) ${ }^{13}$

Our multimodal praxes call for more deep breaths, ${ }^{14}$ more intensity to pause, more play and more pleasure. And less reason to fall outside of the visionary process of transformation. I invite folks into Afro-futurism-images of liberation that calls us in-as spirit holders and future ancestors. Indulge with me, for a Black Queer Feminist moment in time, in visioning and activating Blackness affirmed, and liberation granted. What is our collective creative healing praxis of love, creativity, ancestors, and spirituals? Rest with it, for a while.

13. --affirmations (the Black Joy Experience) is inspired by Nayyirah Waheed (2014) and by my BYP100 squad. The poem title is inspired by the manual The Black Joy Experience Resource Guide (BYP100, Lykes, \& Steez, 2017). 14. Inspired by Alexis Pauline Gumbs' piece "Evidence" in Octavia's Brood: Science fiction stories from social justice movements (2015). "We are very good at growing. I'm growing a lot right now and everyone is supportive of growing time, which includes Daydreams, deep breaths, and quiet walks" (p. 35). 


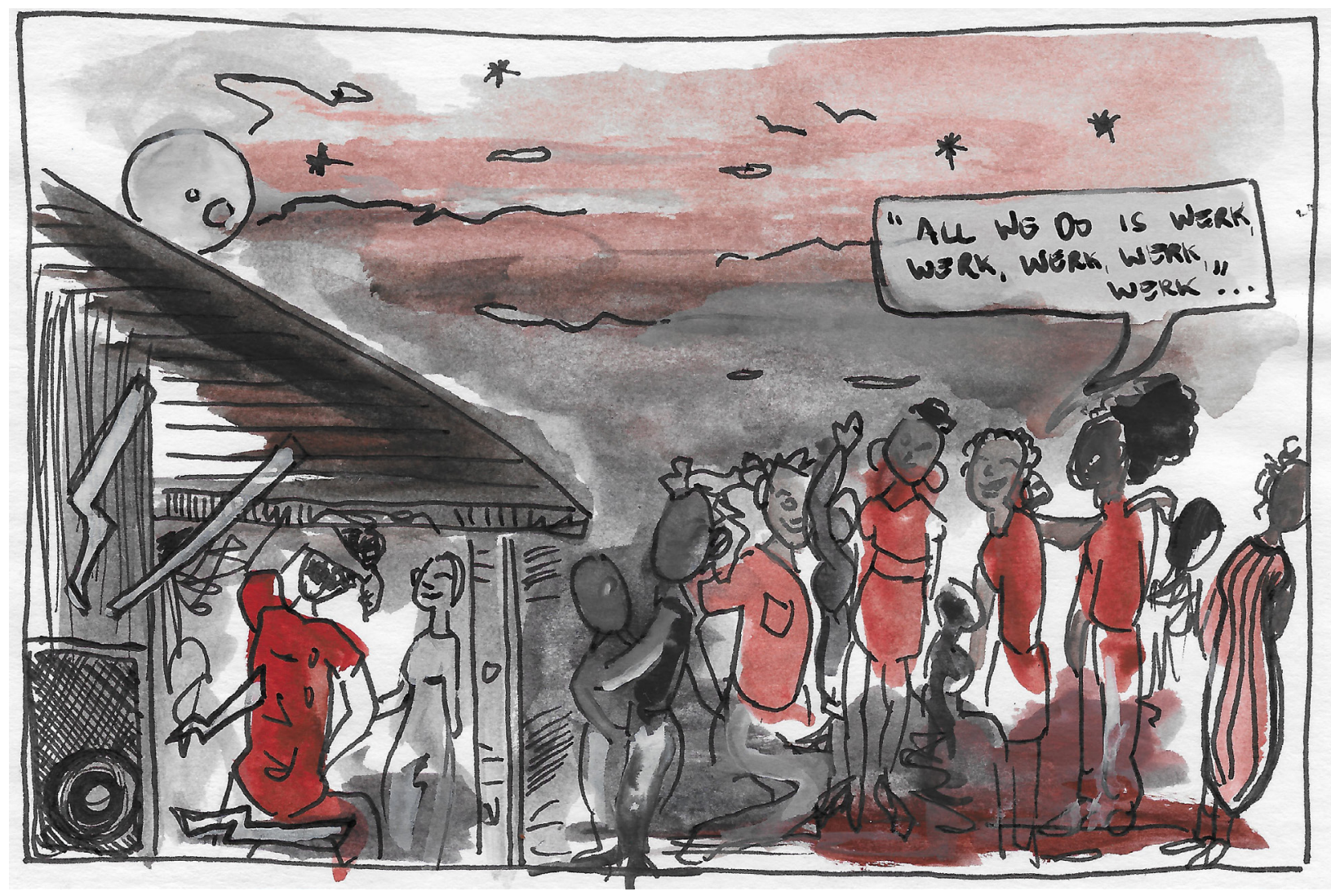

All we do is werk, werk, werk, werk, werk. and we do not do it alone. shout out to my pops, "Grandpa Popi", who is literally always holdin' it down. to my little boo, $K$, who keeps me on my toes, keeps me dancing, and keeps me asking questions/ answering questions. to all my formal and informal editors who diligently and thoughtfully provided guidance on this piece (and in my life). to my WHOLE damn squad. and to all the ANCESTORS and future ancestors.

we are divine.

\section{A C K N OW L E D G M E N T S}

I would like to acknowledge all the thought holders, creators, and visionaries who inspire me. From the words of established intellectuals, to the brilliant conversations and cyphers I have shared with my colleagues at UW Madison and my activist family in the Black liberation movement. Especially important to my process of conceptual growth and practice are the members of BYP100 and the Healing \& Safety Council, in particular Je'Nae Taylor, Kai Green, and Christopher Roberts. My family who support me, believe in me, and make me laugh and (sometimes) scream. To my son, Kamari, who always asks me questions, demands that I do and be my best, and brings me back to my center, thank you. This is for the ancestors who carry me and 
all of us in this work, and to the future generations for which we dream.

\section{R E F E R E N C E S}

Bambara, T. C. (2012). Conversations with Toni Cade Bambara (T. Lewis, Ed.). Jackson, MS: University Press of Mississippi.

Bernstein, N. (2014). Burning down the house: The end of juvenile prison. New York, NY: The New Press.

BYP100, Lykes, J., \& Steez, F. (2017). The Black joy experience resource guide.

BYP100, Morales-Williams, M., Roberts, C., Taylor, J., Green, K., Williams, P.I., Strong, J., Papillon, V., Cabral, N., \& Jackson, E. (2017). Stay woke, stay whole: A Black activist healing manual (1st ed.).

Chance the Rapper (2017). "LSD." Jamila Woods ft. Chance the Rapper. HEAVN. OddCouple. Retrieved from https:// soundcloud.com/jamilawoods/lsd-feat-chance-the-rapperprod-by-oddcouple.

Davis, A. (2006) "Angela Davis Lecture." Moe Lectureship in Women's Studies. Gustavus Adolphus College, St. Peter, MN. Lecture.

Dei, G. J. S. (2017). Towards a [re] theorization of Blackness, anti-blackness, and Black Solidarities. In Reframing Blackness and Black solidarities through anti-colonial and decolonial prisms (pp. 31-63). New York, NY: Springer International Publishing.

Digital History (n.d.). "The three-fifth compromise." Digital History. Retrieved from http://www. digitalhistory.uh.edu/ disp_textbook.cfm?smtid=3\&psid=163

Dilulio, J. (1995). "Moral poverty: The coming of the superpredators should scare us into wanting to get to the root causes of crime a lot faster." Chicago Tribune. December 15, 1995.

Freire, P. (1996). Pedagogy of the Oppressed (rev. ed.). New York, NY: Continuum.

Green, K.M., Taylor, J., Williams, P.I., \& Roberts, C., (in press). \#BlackHealingMatters in the time of \#BlackLivesMatter. Biography Journal.

Gumbs, A.P. (2015) Evidence. In W. Imarisha \& brown, a. m. (Eds.), Octavia's brood: Science fiction stories from social justice movements (pp. 33-42). Chico, CA: AK Press.

Hartman, S. V. (1997). Scenes of subjection: Terror, slavery, and self-making in nineteenth-century America. Oxford: Oxford University Press.

Kelley, R. D. G. (2002). Freedom dreams: The Black radical imagination. Boston, MA: Beacon Press. 
Odum, B. (n.d). I am my ancestors' wildest dreams. Retrieved from http://brandanodums.com/project/studio-be/.

Page, C. (2007). Healing Justice Framework. Just Healing. Retrieved from https://justhealing.wordpress.com/legacy/.

Sexton, J. (2011). The social life of social death: On afropessimism and black optimism. InTensions, 5(1), 1-47. Retrieved from https://www.yorku.ca/intent/issue5/articles/ pdfs/jaredsextonarticle.pdf.

Tuck, E., \& Yang, K. W. (2012). Decolonization is not a metaphor. Decolonization: Indigeneity, Education \& Society, 1(1), 1-40. Retrieved from http://www.decolonization.org/ index.php/des/article/view/18630.

Waheed, N. (2014). "Emotional porn (the black image industry)." Nejma. Seattle, WA: CreateSpace Independent Publishing Platform. Retrieved from https:// americanliteratureintheworld.wordpress.com/2014/11/05/ emotional-porn-the-black-image-industry/.

Whitfield, N., Strong, B. (1971). Smiling faces sometimes [recorded by The Undisputed Truth]/ On Smiling Faces Sometimes [7" Single]. Hitsville U.S.A.

Wilderson, F. B., III. (2010). Red, White \& Black: Cinema and the structure of US antagonisms. Durham, NC: Duke University Press.

Williams, P. I. (2017a). [a] creative healing praxis/[an] ecology of Black trauma. [Ink Drawing].

Williams, P.I. (2017b). All We do is WERK, WERK, WERK, WERK... [Watercolor].

Williams, P.I. (2017c). breathing a breath of ancestors life at every brush stroke". [Mixed Media].

Womack, Y. L. (2013). Afrofuturism: The world of Black sci-fi and fantasy culture. Chicago: Chicago Review Press.

Woods, T. (2007). The fact of anti-blackness: Decolonization in Chiapas and the Niger River Delta. Human Architecture: Journal of the Sociology of Self Knowledge, 5(3), 319-330. 